\title{
Health Insurance in Myanmar: The Views and Perception of Healthcare Consumers and Health System Informants on the Establishment of a Nationwide Health Insurance System
}

\author{
Marjolein van Rooijen ${ }^{1,2, *}$, Chaw-Yin Myint ${ }^{2}$ (D), Milena Pavlova ${ }^{2}$ (D) and Wim Groot ${ }^{2,3}$ \\ 1 Department of Family Medicine, CAPHRI, Maastricht University Medical Center, Maastricht University, \\ 6200 MD Maastricht, The Netherlands \\ 2 Department of Health Services Research, CAPHRI, Maastricht University Medical Center, Faculty of Health, \\ Medicine and Life Sciences, Maastricht University, 6200 MD Maastricht, The Netherlands; \\ mie.suu@gmail.com (C.-Y.M.); m.pavlova@maastrichtuniversity.nl (M.P.); \\ w.groot@maastrichtuniversity.nl (W.G.) \\ 3 Top Institute Evidence-Based Education Research (TIER), Maastricht University, 6200 MD Maastricht, \\ The Netherlands \\ * Correspondence: marjolein.vanrooijen@maastrichtuniversity.nl; Tel.: +31-646-020-990
}

Received: 13 June 2018; Accepted: 13 August 2018; Published: 17 August 2018

\begin{abstract}
Background: Health insurance and social protection in Myanmar are negligible, which leaves many citizens at risk of financial hardship in case of a serious illness. The aim of this study is to explore the views of healthcare consumers and compare them to the views of key informants on the design and implementation of a nationwide health insurance system in Myanmar. (2) Method: Data were collected through nine focus group discussions with healthcare consumers and six semi-structured interviews with key health system informants. (3) Results: The consumers supported a mandatory basic health insurance and voluntary supplementary health insurance. Tax-based funding was suggested as an option that can help to enhance healthcare utilization among the poor and vulnerable groups. However, a fully tax-based funding was perceived to have limited chances of success given the low level of government resources available. Community-based insurance, where community members pool money in a healthcare fund, was seen as more appropriate for the rural areas. (4) Conclusion: This study suggests a healthcare financing mechanism based on a mixed insurance model for the creation of nationwide health insurance. Further inquiry into the feasibility of the vital aspects of the nationwide health insurance is needed.
\end{abstract}

Keywords: basic health insurance; voluntary supplementary health insurance; tax-based funding; community-based insurance; Myanmar

\section{Introduction}

Myanmar is a country in transition. The long period of military rule and repression has had devastating effects on the lives of people in Myanmar (Shobert 2013). Although at present signs of socio-political change are visible, Myanmar is still one of the poorest countries in the Southeast Asian region. Furthermore, the country is ranked 149 on the Human Development Index, out of all 187 countries listed (UNDP 2013). The socio-political and economic situation in Myanmar has affected its health system as well. Currently, only 2\% of GDP (Gross Domestic Product) is spent on healthcare (Kuiper 2013; WHO 2015b), which is very little compared to the surrounding countries. Singapore for example spends 3.9\% and Malaysia 4.4\% of GDP on healthcare (Industry Report 2014). 
At present, $73 \%$ of the healthcare provision in Myanmar is paid through out-of-pocket payments (World Bank 2015; WHO 2015b). In 2012, the Myanmar Ministry of Health estimated that the amount of government funding is only $23 \%$ of the total spending on healthcare. Compared to the neighboring countries, such as Thailand, Vietnam and India, the government spending on healthcare comes up short (Shobert 2014; WHO 2015a). The Ministry of Labour currently provides the only type of health insurance in Myanmar, the so-called Social Security Scheme (SSS), which was put in place in 1956. Out of the 53.7 million citizens in Myanmar, only about 600,000 individuals are covered by the SSS, on individual account, meaning that these people contribute a percentage of their earnings. Eligibility is restricted to certain groups of state enterprise employees, civil servants and employees of public and private firms with five or more employees (de la Puente 2014; WHO, SEARO 2012). Citizens not enrolled in the SSS have to pay for healthcare services out of pocket.

Because of the high percentage of out-of-pocket payments in Myanmar, the poor and other disadvantaged groups who use healthcare frequently, are especially vulnerable to catastrophic financial outcomes once they are in need of healthcare. To protect these groups but also the middle-income groups, there is an urge to design and implement a nationwide health insurance mechanism that can assure universal coverage. The government of Myanmar has committed itself to attain universal health coverage by 2030 (WHO 2011). The need to design and implement a nationwide health insurance system with an adequate benefit package and adequate level of cost sharing is one of the strategies to be considered. To increase the availability of healthcare, efforts are made to develop a national policy on healthcare financing focusing on adequate funding, efficiency of resource use, financial sustainability and capacity for better management of available resources. The establishment of a universal risk pooling mechanism to share healthcare costs and reduce the out-of-pocket payments will help to prevent catastrophic health expenditures among the poor and disadvantaged people and to safeguard access to healthcare services (Smith and Witter 2004; Majumder 2012).

While the need for universal health coverage in Myanmar is recognized, no study has been done so far into what kind of healthcare financing system is most appropriate. Therefore, this study explores the views of healthcare consumers and triangulates them with the views of key health system informants on the design and implementation of a nationwide health insurance in Myanmar. Specifically, the study focuses on the following research questions: would it be an option to extend the current health insurance system, the SSS, to cover other population groups; and what type of health insurance system is best able to ensure universal health coverage for the population of Myanmar?

The following aspects of the future health insurance system are explored from the perspective of healthcare consumers and health system informants: (1) system funding (premium size and collection, patient cost-sharing mechanisms and government subsidies); (2) management of the insurance system (type and organization of insurance agencies, accountability and government involvement); (3) relations between healthcare insurers, healthcare providers and healthcare consumers; and (4) benefit package. Based on this, we outline the degree of consensus among the participants and we discuss implications of the study for the development of a sustainable, efficient and equitable nationwide health insurance system for Myanmar. We recognize that the main prerequisite for building a sustainable health insurance is to create a strong cooperation between all three stakeholders-payers, providers and beneficiaries. The study provides a base for policy debates not only in Myanmar but also in other developing countries struggling with the establishment of a nationwide health insurance system.

\section{Materials and Methods}

This study is an explorative qualitative study based on focus-groups discussions (FGDs) and in-depth interviews (Wilkinson 2004). The study was carried out in the period between June-August 2015. A qualitative ethnographic study design is chosen because it allows the researcher to analyze and compare the opinions of different participant groups based on their backgrounds and cultural perspectives (Tao 1995). In this study, data were collected among healthcare consumers through 
FGDs where the perceptions of healthcare consumers on a suitable health insurance system were explored. In addition, for comparative purposes, data were collected among key health system informants through semi-structured in-depth interviews. While the guide for the FGDs included only questions that could be comprehended by the healthcare consumers, the interview guide included some additional detailed questions about the health insurance design. Both guides were based on open-ended questions related to the key aspects of health insurance studied: system funding, management responsibilities and accountability for healthcare coverage, as well as the relations between healthcare consumers, insurer(s) and healthcare workers.

At the start of the data collection, community leaders and SSS bodies selected and approached the participants of the FGDs. The objective was to have participants with different socio-economic and health insurance status, as well as different educational backgrounds, to ensure that different consumers' perspectives are studied (Wilkinson 2004). Thus, the principles of convenience and purposive sampling were applied (non-probabilistic sampling) (Lavrakas and Battaglia 2008).

In total, nine FGDs with healthcare consumers were carried out (68 participants in total). The 7 FGDs were conducted in 6 townships, which cover both urban and peri-urban areas in the Yangon region (Hle Gu, North Dagon, Bahan, Ahlone, Shwe Pyi Thar and Mingalardon). In addition, one FGD was carried out in the Bago township in the Bago region and one FGD was carried out in the Kyaut Se township in the Mandalay region to explore different views and experiences across different regions.

The key health system informants were also selected through a combination of non-probabilistic sampling techniques, namely convenience and snowballing sampling (Browne 2007). The group of key informants included three healthcare providers and three policymakers with diverse professional background. Policymakers working at government/municipality, non-government and international organizations were identified with the help of local contacts from Yangon based on the principle of convenience sampling. Urban and rural healthcare providers working at public or private facilities were identified using a snowball sampling (Browne 2007). Thus, healthcare providers interviewed suggested potential participants based on their professional network.

Ethical clearance was obtained from the Department of Medical Research at the Ministry of Health of Myanmar. Prior to the start of the interviews and FGDs, the participants received detailed information about the study, gave permission for tape recording the interview and were asked to sign an informed consent form. The participant only took part in the study if he/she agreed to sign the informed consent form. The FGDs were conducted using an interpreter/translator since the participants only spoke Myanmar, while not all researchers in the research team spoke the language. The data from the FGDs were translated and then summarized. Interviews were conducted in English as all participants had a good command of the English language. After conducting the interviews, they were verbatim transcribed.

The analysis of the data was done by coding the transcripts according to the key aspects of health insurance included in the interview and FGD guide, thus applying the method of directed qualitative content analysis (Hsieh and Shannon 2005). This analysis starts with the key themes (in this case, the key aspects of health insurance mentioned above) as guidance for initial codes. The most frequently repeating codes formed the basis of the synthesis of results. The views of participants on the current healthcare financing system in Myanmar were also extracted and analyzed.

To improve the validity of the study, verification with the interviewed key informants was carried out to clarify whether the content of the synthesized results is similar to what they meant during the interview. Asking open-ended questions and comparing the results with the findings of background studies (Golafshani 2003) helped to improve the reliability of the study outcomes. 


\section{Results}

As mentioned above, nine FGDs with healthcare consumers (19 male and 49 female, 68 participants in total) and six in-depth interviews with key health system informants (three healthcare providers and three policymakers) provided data for this study.

The results are synthesized and presented according to the key aspects of health insurance: system funding, management responsibilities and relations between healthcare consumers, insurer(s) and healthcare workers. Before that, the views on the current system of healthcare financing are presented.

\subsection{Current System of Healthcare Financing}

The only insurance system currently in place in Myanmar is the SSS. This system has not been improved or expanded over the years, as indicated by one of the key informants. The SSS is regulated through the Ministry of Labour and paid for by employers of middle and large companies (five or more employers). Healthcare services covered by the SSS are provided in two hospitals in Yangon, one hospital in Mandalay and in 77 SSS clinics throughout the country. Employees, who are enrolled, are reimbursed for their healthcare spending in non-SSS facilities as well.

Healthcare consumers-participants enrolled to the SSS, as well as key health system informants included in the study, are generally not satisfied with the services provided by the SSS. The people enrolled in the SSS often do not know the premium rate which is deducted from their salary and what healthcare services are covered. In addition, the healthcare services provided by the SSS do not satisfy the patients' medical needs in terms of distance and opening hours, which coincide with the general working hours. Sometimes facilities are open only 3 days/week. There are problems with poor communication skill of the health staff and a long waiting time. SSS members in our study also complain about the poor health facilities of SSS clinic, for example, lack of health staff, essential medicines, laboratory and imagine facilities. The last factor bothering SSS members in our study is the long reimbursement process when they pay out-of-pocket for medicines at outside pharmacy or receive healthcare at public facilities that fall under the Ministry of Health. The data from the FGDs show that some persons are unaware of their enrolment in the SSS and are unaware of the eligibility criteria to enroll in the SSS. Also, even if people are enrolled, they still pay high amounts of money for healthcare services and have to wait a long time before their healthcare costs are reimbursed. The reimbursement is usually not in full. Sometimes they only receive $50 \%$ of the actual expense. Therefore, the majority of the members enrolled in the SSS, choose for non-SSS hospitals such as private clinics, even though these healthcare costs are not covered. These views about the functioning of the SSS are also supported by the key health system informants in our study. On the other hand, one SSS member who experienced a resection of a breast tumor at SSS hospital in Mandalay indicates that she was satisfied with doctors and service and that the cost was very low as she only needed to pay for travel, food and some medicines.

'I don't want to enroll in health insurance, since I don't trust it. Now all our colleagues have SSS but when we went to the SSS office to pay premium, the communication with the office staff was very bad and the process takes a lot of time. For reimbursement, they have to wait for a long time as well. So if the health insurance will be like this, I don't want to enroll.' (FGD-participant/SSS member)

'As the SSS clinic is too far from the residential area and open only 3 days per week, I prefer to seek treatment at nearby clinic' (FGD-participant/SSS member)

'I did not get full reimbursement when I was admitted to public hospital for a fractured leg' (FGD-participant/SSS member)

'So, most of them (healthcare consumers with SSS health insurance) go to the government hospital for their health problems, because they have SSS. But some of them don't 
want to go to the government hospital. It is very dirty and they lack facilities, so they prefer going to the private clinics even though they pay for social welfare (SSS).' (Key informant/healthcare provider).

The challenges faced by the non-SSS members at present are high out-of-pocket payments, long distance from the health facility especially for specialized care and poorly equipped health facilities in the community. One participant living in a sub-urban area of Yangon, Hle Gu township, had to borrow money and/or sell assets to pay for healthcare. However, people living in another township (Bahan) state that they can access a mobile clinic, which provides free healthcare including, imaging facilities. One participant from Bahan township and one from North Dagon township report that the public hospitals stand for the poor with low cost and good quality of care. Utilization of public hospitals costs only one third of the private hospital use because it only requires buying some medicines while other services are free.

'We need to borrow money from either relatives or money mongers who take $5 \%$ or $10 \%$ or $15 \%$ interest. As I don't have health insurance or a social security card we even need to sell our properties to get treatment' (FGD-participant/non-SSS member)

'There was an imprinted ideology in our mind that 'no money no healthcare' in contrary to our belief, it cost only 50 USD in public hospital instead of 150 USD if we used a private facility' (FGD-participant/non-SSS member)

The FGDs show that the most important criteria healthcare consumers use when choosing healthcare services are accessibility of and trust in the healthcare provider, as well as the ability to pay for their healthcare services. Therefore, they visit facilities and providers near their homes and only use specialist care in case of referral by their general practitioner (GP). Some participants in the FGDs mention that long waiting hours are a barrier to seek healthcare, especially in big general hospitals. In clinics nearby the homes of participants, this problem is not perceived.

The key health system informants also mention the problem with long waiting hours. One key informant, working at a public hospital, explains that often, situations occur in which the demand for care exceeds the work capacity of the hospital, since the group of healthcare consumers the hospital covers, exceeds the capacity of the hospital. This informant also states that the government underestimates the amount of healthcare consumers served by a township. In the township of Hlaing Tharyar, according to another key informant, one third of the healthcare consumers are not registered, because of the high percentage of non-registered migrant workers coming from the North of Myanmar. The work-pressure resulting from the shortcomings in staff and facilities, together with the very low salary ( $\$ 185$ on average per month) leads to low quality of care and a long waiting time for healthcare consumers.

The healthcare consumers in our study state that if they would have enough money, they would not use the government facilities anymore but pay for private healthcare. According to key informants in the study, healthcare consumers with higher incomes mostly use private healthcare facilities. They rather spend extra money for high quality healthcare in private facilities in Myanmar, or go abroad to countries such as Singapore and Thailand.

The overall perception of both healthcare consumers and key informants is that there is a more general need of a better and more up-to-date health system and not merely an improvement of the SSS, which is only a part of the healthcare financing mechanism. The following quote explains why one of the key informants in the study does not think the SSS is a success:

'The SSS was formed many years ago, when we were young. If the system was okay, the amount of people using it would be reaching the sky!' (Key informant/healthcare provider)

Key informants also mention that healthcare consumers do not pay for all healthcare costs themselves. The government provides some pharmaceuticals to hospitals and healthcare facilities. 
Additionally, some healthcare is provided free of charge (e.g., services of healthcare workers on voluntary basis in the rural areas). At the same time, healthcare consumers in the study explain that local governments sometimes arrange free mobile clinics that provide free specialist care for eye disease or other non-acute needs.

However, healthcare consumers also mention during the FGDs that the healthcare costs they have to pay, are sometimes paid for by using savings, borrowing money from relatives and friends, selling properties or getting a loan. The following quote explains the thoughts and considerations of one FGD participant when he has to pay for medical services he uses:

'If the illness I am faced with is very serious, I will have to borrow money to get treatment. If I do not die, I can earn money and pay it back later.' (FGD-participant/non-SSS member)

When asked in the FGDs how big the barrier of healthcare cost on daily life expenditure is, direct catastrophic experiences, are not stated by the healthcare consumers. Only a few consumers-participants speak of situations in which they are faced with financial hardship due to their illness.

\subsection{Funding of a Future Health Insurance System}

In the FGDs, the topic of a health insurance funding system appears difficult to grasp, since most of healthcare consumers lack experience with healthcare insurance. However, after receiving information on the health insurance concept, most FGD participants show a positive attitude towards paying for health insurance. Generally, for a basic package of healthcare services, an insurance premium equal to $4 \%$ of the monthly income is seen as a reasonable amount to pay, when paid on a monthly basis. For individuals with lower incomes, this insurance premium will mean 1000-3000 Kyats (approximately 1-3 USD) per month. If the package includes high-cost medical services, they are willing to spend up to $5-6 \%$ of their monthly income. They also would like to have their family members covered by this insurance premium.

'We want to contribute 2-5\% for health insurance (exact amount is 3\%). We prefer monthly payment as we don't want to burden our self' (FGD-participant/non-SSS member)

'All family members should have health insurance and contribute a fixed amount' (FGD-participant/non-SSS member)

'We are willing to contribute monthly premium with range between 2000-3000 MMK' (FGD-participant/SSS member)

The key informants in our study propose three different funding systems as being most appropriate for the Myanmar population; a tax-based health insurance system for the whole population of Myanmar, a health insurance system based on a combination of taxes and individual insurance contributions and a community-based health insurance system. The option of a tax-based health insurance system for the whole population is proposed by one of the key informants who is a policymaker. This key informant highly values the concept of solidarity and states that solidarity is essential for a successful nationwide healthcare insurance system. He also supports the idea that 'the contribution should not restrict access.' According to him, it is important to limit the inequality in access to adequate healthcare and a fully tax-based health insurance system would be the best way to approach this problem. Health insurance should be a form of social protection, provided by a mechanism that allows cross-subsidy from the rich to the poor. As indicated by this key informant, surrounding countries, for example, Thailand, India and Sri Lanka, achieved better coverage by increasing government spending on health. A tax-based system, creating a large pool of contributors to the insurance system is the best possibility to cover the largest range of health episodes. It is fundamental to have the poor, children and elderly covered to start with. If the government starts 
by covering a small part of the population with a basic package of healthcare, with the prospected increase of Myanmar's economy and wealth in time, the package as well as the amount of people covered can be increased, as explained by the key informant.

'The larger the pool of contributions, whether it is through individuals into a social insurance pool or whether it is into a tax system but the larger the pool, obviously the larger the range of health episodes that you can cover.' (Key informant/healthcare policymaker)

This key informant does not see the small formal sector as a problem. As he explains, only one third of the Myanmar's population is working in the formal sector and would contribute by paying taxes to this type of health insurance funding. There are possibilities of getting people from the informal sector to pay as well but the costs to get them enrolled often exceeds the funds they contribute to the pool. The key informant sees the nationwide health insurance as a form of road tax.

'In other countries when you buy a car you must pay road tax every year. But a poor person who has a bicycle doesn't pay road tax but he can still access all roads. The same concept with tax based healthcare financing model which poor can access healthcare although they don't need to contribute like rich one.' (Key informant/healthcare policymaker)

Other two key informants, also policymakers, propose a basic package of healthcare services funded by both taxes and individual insurance contributions. This insurance contribution should give the healthcare consumer access to a basic package of healthcare starting with the coverage of primary healthcare. In case people can afford to spend more money and are willing to do so, they can get coverage for secondary and tertiary healthcare services, provided by a private healthcare insurance company. However, key informant believes that 'the ones who pay more should get more.'

According to one key informant, informal workers should be made responsible to contribute to the health insurance system, making health insurance mandatory even though gathering the individual contributions will be challenging. He explains that the Myanmar banking system is weak, leading to a lot of mistrust in the banks. Therefore, many people do not have bank accounts. Innovative ways of reimbursements can be thought of, as suggested by one of the key informants. Household electricity bills are paid at local offices and healthcare insurance payments can be included in these monthly bills. If people do not pay for their insurance or electric bill, they will get cut off the electricity as well.

A community-based health insurance system for the rural areas of Myanmar, is proposed by one of the key informants, who is healthcare provider. To overcome the concerns about the access to and delivery of adequate care, collaboration between government and the NGOs that are working is the area is necessary. This key informant states that a different form of health insurance for the rural populations might be more appropriate since these population groups do not have the same access to healthcare facilities as people living in the urban areas. Setting up health clubs, to pool money of the small communities into a fund, will enable the healthcare consumer in the rural areas to pay for medical costs out of this community fund. Pooling the money can be done in many different ways, as explained by the key informant.

\subsection{Management of a Future Health Insurance System}

Healthcare consumers-participants in the FGDs do not show a preference for a specific management body for health insurance as long as the organization is transparent and efficient. They find trustworthiness, reliability and accountability of the managing body important criteria for the management of the future health insurance system. According to them, the managing body should guarantee equal access to and quality of healthcare services.

'We want the honest and efficient organization to handle the health insurance service although we don't have any political preference' (FGD-participant/non-SSS member) 
'I prefer both private and government sector involve in establishing health insurance policy' (FGD-participant/SSS member)

All key health system informants in our study have a positive attitude towards the involvement of international parties to help set up a health insurance system in Myanmar, as they acknowledge that the national stakeholders currently lack the experience to set up such system themselves. Related to this, two key informants see the importance of involving NGOs and international organizations to develop the management of the system. They explain that Myanmar lacks experience with health insurance governance and needs assistance from more experienced parties (International nongovernment organizations, medical associations, international insurers) to come up with a health insurance system.

'In Myanmar there is a lack of management and regulatory power to map all activities of NGOs and INGO are doing to improve the health.' (Key informant/healthcare policymaker)

'I think foreign companies should come here because this is fertile soil, very fertile soil for many businesses.' (Key informant/healthcare policymaker)

Key informants in our study however recognise that the collaboration between international NGOs and governments can be challenging. As explained by one of the key informants, he experiences a barrier when collaborating with government representatives, as he perceives a strong hierarchy.

'The hierarchy makes working in collaboration difficult.' (Key informant/healthcare policymaker)

Key informants in our study also recognise the lack of regulations and policies in Myanmar. One of the key informants sees it as the government's responsibility to lay down the rules and regulation for health insurance but allow for a joint venture of public and private parties together to organise the health insurance. This key informant sees a role for private companies to come up with policies and to stimulate competition between those parties to keep the price of health insurance low. But at the same time, it is necessary to have the government as a controlling body to control and regulate the health insurance market so that the quality of healthcare is guaranteed.

'We need the right mechanism in place but the mechanism also needs the right policies in those areas.' (Key informant/healthcare policymaker)

One key informant points out that the government lacks the 'eye's on the ground' and do not want to be told what to do either by medical doctors or policymakers from NGOs. This leaves them with unrealistic views on the society and the population's medical needs. Another key informant however sees the organization of educational programs of healthcare workers as a responsibility for the government.

\subsection{Relations between the Stakeholders in a Future Health Insurance System}

The results of the FGDs suggest that healthcare consumers have a strong preference to choose their own physician, based on a feeling of trust. Therefore, they do not like the idea of being restricted to one healthcare worker under the future health insurance system. They also expect that health insurance can offer access basic primary care and specialised care if they needed. They wish the reimbursement process to be short and to get full reimbursement.

'We wish to have universal coverage for health insurance or social protection it should step from local health clinic up to tertiary level' (FGD-participant/non-SSS member)

'We are keen to have skill healthcare workers with good communication skill' (FGD-participant/SSS member) 
One of the key informants suggests the involvement of the Myanmar Medical Association for the training and educational programs of medical professions. Keeping healthcare workers in the system is a problem since salaries are low and the facilities are old-fashioned. This makes job opportunities in surrounding countries such as Thailand and India more attractive compared to working in Myanmar, which results in a brain drain. Due to the lack of human resources, especially in the rural areas, the question of free choice of healthcare provider under a future health insurance system can be only relevant in the urban areas.

With regards to competition, one key informant advises to encourage competition among healthcare workers. He feels that for example an experienced physician should be paid more compared to a physician who just graduated form a medical school, because of the professional experience. One key informant also mentions the lack of competition among healthcare providers but also among suppliers of healthcare equipment and pharmaceuticals. The latter was prohibited in the country during the military ruling and the international boycott for several years. This kept innovation in medical equipment and pharmaceuticals low. Therefore, encouraging competition might make working in the healthcare sector more attractive as well. However, not all healthcare consumer-participants share the positive opinion on competition among healthcare providers. Providing physicians with better facilities, sufficient pharmaceuticals and medical equipment will make the profession more attractive as well, according to one key informant.

All participants acknowledge the importance of including all Myanmar people in the healthcare insurance but reducing the burden of paying for healthcare for vulnerable groups. The elderly, children and vulnerable population groups should be paying less or should not pay at all for the healthcare services they use, according to one of the key informants.

\subsection{Benefit Package}

An interesting finding in the FGDs is that healthcare consumers want all services included in the health insurance package, even annual medical check-ups. The question is whether this is realistic and whether people fully consider the costs of providing all of these services for free. One of the key health system informants thinks that expensive cancer treatment; dental care, plastic surgery, organ transplants and traditional medicine are all treatments that can be excluded from the benefit package. Traditional medicine is practised on a large scale, mainly in the rural areas but it is often entails health risks. Traditional practices sometimes prevent people from using evidence-based medicine practices or the traditional treatment on itself puts the patient in danger. The 'safer' practices, such as herbal teas, are often inexpensive and can be easily paid for by people themselves, as stated by one key informant.

Bottom-up investigation is needed to specify what necessary services should be included in the package and what services can be excluded. One key informant also states that the medical needs of the rural area are different from those in the urban areas and healthcare services available in the urban, might not be available in the rural areas: 'We need to find out what people need.' A way of determining what should be included in the package is by starting by covering the most accessible services for the whole population. First primary healthcare services, together with public health and once the country becomes more developed and wealthy, expanding the coverage to secondary and tertiary care. Thereby focusing what is cost-effective healthcare.

\section{Discussion}

There is no doubt that all health system aspects are important in moving towards universal health coverage in Myanmar. However, this study has focused on the healthcare financing mechanism only. The study has explored the views of healthcare consumers in Myanmar on the current health insurance system, the SSS, as well as on the design and implementation of future health insurance. The study has also triangulated these views with the views of key health system informants on healthcare financing. Overall, it is expected that by implementing an innovative and culturally adapted health insurance system, the financial hardship of using healthcare will be reduced. But what type of health insurance 
could be implemented? Based on the views of healthcare consumers and key informants, our study sheds light on the following aspects of the future health insurance system in Myanmar: system funding, management responsibilities and relations between healthcare consumers, insurer(s) and healthcare workers and benefit package. The results are interpreted based on literature from other countries since information on this topic for Myanmar is lacking to a great extent.

The results confirm that the current health insurance system, the SSS, covers only a very small share of the population and does not fulfil the needs of its members. The weaknesses of the current health insurance system include poor health facilities in SSS clinics and a long and unclear reimbursement process. We also find that healthcare consumers, who are not SSS members, are overall unfamiliar with the concept of health insurance, though after explaining the concept, all healthcare consumers in the FGDs express a positive attitude towards health insurance. This suggests however, that before implementing any kind of health insurance system in Myanmar, raising awareness among the population is essential to ensure that people will enroll in the system and that they know what they are entitled to. This problem is observed in other countries as well. India for example is currently improving the universal health coverage of the population and the experience shows that understanding of policy coverage by the insured is necessary for the successful insurance implementation (Sippy and Ravi 2015).

The results of our FGDs suggest that healthcare consumers are willing to spend 2-5\% of their monthly salary on health insurance. Although this amount should not be seen as a hard indicator, the amount seems reasonable compared to other neighboring countries. In India, the insured persons even spend $8-10 \%$ on their monthly income on health insurance (Bureau 2011). Our results however should not be interpreted in terms of recommended insurance contribution in Myanmar. To determine the adequate insurance contribution levels, further analysis based on nationally representative survey data collected among all stakeholder groups as well as estimated cost of benefit package would be necessary. Up to date, neither actuarial tools and projections, nor proper costing exercise for benefit package has been done even in the SSS in Myanmar (Tessier and Thidar 2014). Policy makers need to understand the current costs to set efficient provider payment system of health insurance (Özaltın and Cashin 2014).

Three options of health insurance or different risk pooling mechanisms emerged from our study as being appropriate for Myanmar according to some of the respondents; a tax-based funding system, a combination of basic social health insurance and additional voluntary insurance, as well as community-based health insurance. Each of these health insurance options has its advantages and disadvantages and its feasibility in Myanmar. These factors should be analysed in further studies before recommendations for the future health insurance system in Myanmar can be formulated. Nevertheless, some evidence on this can be already found in previous studies as discussed in the following paragraphs.

As suggested in the literature, the advantage of a tax-based funding system is a lower rate of adverse selection and risk selection compared to the other healthcare financing mechanisms proposed by the respondents. Moreover, a tax-based funding system is more progressive than the other financing mechanisms because it diminishes the burden on the poor (Smith and Witter 2004; Savedoff 2004). There are many ways to mobilize revenue in a tax-based funding system, such as value added taxes, sales taxes and import duties. However, it is impossible to depend on a tax-based financing system solely due to the small tax revenue in Myanmar (Tessier and Thidar 2014). Hitherto, Myanmar is mainly dependent on corporate or individual income tax (salary or business) but the law and regulations are not strengthened enough to get a large amount of revenue for the health system (DFDL 2014). The success of tax-based funding depends on the effectiveness of the political system that governs the allocation of funds as well as on the efficiency of the health service provision. Fully tax-based funding has a potential in case of a scheme that covers a very small benefit package or a very small part of the population, or a combination of the two. Such scheme can be used for covering the poor and vulnerable groups by the government through tax-based funding (Savedoff 2004). 
Previous studies (Wagstaff 2009; Hsiao and Shaw 2007) suggest that a social health insurance system strongly depends on the contributions from the employees and employers. Given the low earning rates in Myanmar, it is uncertain if the social health insurance can alone guarantee sustainable healthcare financing. The social health insurance is usually mandatory for formal sector workers, however, voluntary or not eligible for the informal workers. Thus, it is difficult to get nationwide coverage if social insurance is implemented alone if there is a large informal sector (Acharya et al. 2012). This implies that the SSS in Myanmar could be only partly expanded in urban areas where there is more formal employment. But to achieve this, the SSS should also improve its services because the various shortcomings, as those indicated in our study, might discourage citizens to purchase this type of health insurance.

Regarding the community-based health insurance, mentioned by some participants in our study, the evidence in the literature are rather controversial. Some countries, for example, China and India, have success stories while others, for example, Philippines and Indonesia, have a historical interest but no longer consider this health insurance option (Soors et al. 2010). The reasons to drop community-based health insurance are operational difficulties, financial problems, small schemes (many of them covering less than 500 households with insufficient risk pooling, unattractively limited benefit packages and high dropout rates). To be successful, community insurance pools should be large enough and should attract a suitable mix of insurance members, that is, a variety in age and health backgrounds, to ensure that the risk is insurable (Carrin et al. 2005; Lautier 2006). Political commitment together with government subsidies played an important role in the successful expansion of community-based health insurance in China and India (Soors et al. 2010). Though proposed by participants in this study for rural areas, the feasibility of community-based health insurance in Myanmar need to be explored further.

Thus, as discussed above, the implementation of only one health financing system will be difficult to sustain financially and it will be difficult to achieve full coverage in Myanmar. A combination of the three models could provide a comprehensive funding system to develop nationwide health insurance for the coverage of the whole population.

It seems reasonable to involve parties outside of the government, such as NGOs or international companies, including private health insurers, with knowledge and competences in health insurance provision, to compensate for the lack of experience the government of Myanmar has and to gain benefits that might come from working and learning from these parties (Biesma et al. 2009). The role of NGOs in community-based insurance has been either as an insurer, as a provider of health services, or as third-party administrator who purchases the insurance from the insurance company (Soors et al. 2010). The last kind of arrangement creates the wider risk pool (Churchill 2006). The advantage of involvement of NGOs includes their effort to improving negotiating capacity with insurance companies and providers. For example, in India, Karuna Trust negotiated an insurance package including compensation for income loss and medicine with a low premium rate which is below the estimated willingness to pay of the poverty line. At the same time, the weakness of this arrangement is that the limited benefit package for already set premium rate may not meet the need of beneficiaries. This can lead to pay up front and cumbersome reimbursement. Some NGOs control this by offering the tailored package based on the need of local population (Radermacher et al. 2005). The Indian government declared the involvement of NGOs as a priority in the establishment of the Indian National Rural Health Mission 2005 (Soors et al. 2010). It is however important to keep the final responsibility and overview of the health system with the government to make sure that the NGOs involved do not only focus on one specific illness but take a whole scale of diseases into account. Similarly, the government should regulate the involvement of private health insurers because they may tend to focus on profit making. Next to this, the Myanmar government should take into account that the current legislation and regulations need to be adjusted to make the implementation of a nationwide health insurance system possible. With regards to providers, both public and private providers should cooperate in the nationwide health insurance system and negotiate about payment methods. The SSS should not be 
served as a provider because the efficiency of SSS health service provision is very low according to our study and other evidence (Tessier and Thidar 2014). The main concept for building a sustainable health insurance is to develop a strong linkage between all three stakeholders-payers, providers and beneficiaries.

Although our study provides evidence relevant to policy, as it is the first of its kind in Myanmar, the study has certain limitations that need to be acknowledged. We include two groups of study participants: healthcare consumers and key health system informants. However, the number of representatives of key informants is rather low due to bureaucratic reasons coupled with time constrains of potential participants. Therefore, complete saturation of the opinions in the sub-groups groups of key informants, namely policymakers and healthcare workers, is not reached. The number of healthcare workers interviewed is especially small. Therefore, it is not possible to make conclusions about the sub-groups of key informants and it is not possible to contrast the answers of these sub-groups. Another limitation is the lack of prior knowledge on health insurance among uninsured healthcare consumers. The topic of a health insurance funding system appears difficult to grasp among these inexperienced potential insurance clients. Their views might have been more pronounced if they had prior experience with health insurance. Moreover, the study was restricted to the area of Yangon, which means that perceptions of people living in the remote rural areas could not be explored. Lastly, the country is in transition with socio-political changes taking place. For example, as of July 2015, after the data collection for our study, the government allowed private companies to offer health insurance. Investigating the role of this type of insurance providers will be an important topic in future research (Thitsar 2015).

As explained by the World Health Organisation (WHO), various factors are important to make universal health coverage successful; a strong, efficient, well-run health system, an affordable financing healthcare services, availability of essential medicines and technologies and well-trained, motivated health workers (WHO 2015a). All these factors apply to Myanmar as well as evidenced by our study. Despite the variation in opinions about how to organise the health insurance system, all stakeholder groups agree that a completely new insurance system should be designed and implemented by integrating the existing current small scale SSS. A stepwise implementation approach is recommended to account for the variation between the rural and urban areas and for the general lack of resources for healthcare in the country. All stakeholders also agree that equity in accessing health insurance system will be vital for protecting the poor and vulnerable groups from financial hardship when using healthcare.

Conclusions based on information by consumers is valuable and essential to take into account in any decision about the implementation of a health insurance system but we should also consider the limits in the knowledge about health insurance that consumers in Myanmar have. Thus, although our study provides evidence on the stakeholder's views, more research is needed before a rational choice for a health insurance system in Myanmar can be made. Future research could focus on vital health insurance aspects, such as how to make the pooling mechanism feasible, how to define an essential benefit package that is affordable for the country, how to assure the risk pooling mechanisms so that health insurance can be beneficial for vulnerable groups as well.

Author Contributions: M.v.R.-formulation of research question; design of methodology; conducting the research and data collection; data analysis; preparation of manuscript, specifically writing the initial draft and revision; C.-Y.M.--formulation of research question; design of methodology; conducting the research and data collection; data analysis; preparation of manuscript specifically draft and revision; M.P.—design of methodology, preparation of manuscript specifically critical review; W.G.—design of methodology, preparation of manuscript specifically validation and critical review.

Funding: The authors received funding from Netherlands Fellowship Programmes (NFP). NUFFIC grant-NFP-PHD 14/15/0007.

Acknowledgments: We would like to acknowledge the local authorities who facilitate our focus group discussions in all 6 townships, as well as all participants in the study. We also thank the three anonymous reviewers who helped us to improve the paper. 
Conflicts of Interest: The authors declare no conflict of interest. The funders had no role in the design of the study; in the collection, analyses, or interpretation of data; in the writing of the manuscript and in the decision to publish the results.

\section{References}

Acharya, Arnab, Sukumar Vellakkal, Fiona Taylor, Edoardo Masset, Ambika Satija, Margaret Burke, and Shah Ebrahim. 2012. The Impact of Health Insurance Schemes for the Informal Sector in Low- and Middle-Income Countries: A Systematic Review. The World Bank Research Observer 28: 236-66. [CrossRef]

Biesma, Regien G., Ruairí Brugha, Andrew Harmer, Aisling Walsh, Neil Spicer, and Gill Walt. 2009. The effects of global health initiatives on country health systems: A review of the evidence from HIV / AIDS control. Health Policy and Planning London School of Hygiene and Tropical Medicine 24: 239-52. [CrossRef] [PubMed]

Browne, Kath. 2007. Snowball sampling: Using social networks to research non-heterosexual women. International Journal of Social Research Methodology 8: 47-60. [CrossRef]

Bureau, E. T. 2011. Growth, Reforms Lift Livings Standards in India: Human Development Index. The Economic Times India. Available online: http:/ / articles.economictimes.indiatimes.com/2011-10-22/news/30309881_ 1_human-development-education-index-india-s-hdi (accessed on 25 August 2015).

Carrin, Guy, Maria-Pia Waelkens, and Bart Criel. 2005. Community-based health insurance in developing countries: A study of its contribution to the performance of health financing system. Tropical Medicine and International Health 10: 799-811. [CrossRef] [PubMed]

Churchill, Craig, ed. 2006. Protecting the Poor: A Microinsurance Compendium. Geneva: International Labour Office. Available online: http:/ / www.munichre-foundation.org/NR/rdonlyres/52FA02DB-B6A4-4DEB-81495A64B64D6A68/0/ProtectingthepoorAmicroinsurancecompendiumFullBook.pdf (accessed on 15 August 2018).

De la Puente, Manuel. 2014. Social Security Programs throughout the World: Asia and the Pacific, 2014. Geneva: International Social Security Association, pp. 65-68.

DFDL. 2014. Highlights of Five New Myanmar Tax Laws. Available online: https:/ /www.dfdl.com/resources / legal-and-tax-updates/highlights-of-five-new-myanmar-tax-laws/ (accessed on 15 July 2018).

Golafshani, Nahid. 2003. Understanding Reliability and Validity in Qualitative Research. The Qualitative Report. Toronto: University of Toronto, vol. 8.

Hsiao, William, and R. Paul Shaw. 2007. Social Health Insurance for Developing Nations. Washington: The World Bank. Hsieh, Hsiu-Fang, and Sarah E. Shannon. 2005. Three approaches to qualitative content analysis. Qualitative Health Research 15: 1277-88. [CrossRef] [PubMed]

Industry Report. 2014. Healthcare: Malaysia. London: Economist Intelligence Unit.

Kuiper, Ralph Arnold. 2013. Report on the Peninsula Chapter Event on Wednesday, November 20, 2013 "Myanmar in Transition: History, Politics and Health Care". Los Altos: Peninsula Chapter World Affairs Council of Northern California.

Lautier, Bruno. 2006. Towards universal social security and protection of the 'most vulnerable'. In Strategies and Tools against Social Exclusion and Poverty Programme (STEP) Social Protection andInclusion: Experiences and Policy Issues. Geneva: International Labour Office (ILO), pp. 77-103.

Lavrakas, Paul J., and Mike Battaglia. 2008. Convenience Sampling. Encyclopaedia of Survey Research Methods. Available online: http:/ /srmo.sagepub.com/view/encyclopedia-of-survey-research-methods/n105.xml (accessed on 6 March 2015).

Majumder, Md Anwarul Azim. 2012. Economics of Healthcare Financing in WHO South East Asia Region. South-East Asia Journal of Public Health 2: 3-4. [CrossRef]

Özaltın, A. Annette, and Cheryl Cashin. 2014. Costing of Health Services for Provider Payment: A Practical Manual Based on Country Costing Challenges, Trade-offs and Solutions. Washington: Joint Learning Network for Universal Health Coverage.

Radermacher, Ralf, Olga van Putten-Rademaker, Verena Müller, Natasha Wig, and David M. Dror. 2005. Karuna Trust, Karnataka, India. CGAP Working Group on Microinsurance: Good and Bad Practices, Case Study No. 19. Geneva: International Labour Office, Social Finance Programme.

Savedoff, William. 2004. Tax-Based Financing for Health Systems: Options and Experiences. Geneva: World Health Organization. 
Shobert, Benjamin. 2013. Healthcare in Myanmar. Forbes Pharma and Healthcare. Available online: http: / /www.forbes.com/sites/benjaminshobert/2013/08/19/healthcare-in-myanmar/\#4f3032ee5df8 (accessed on 6 March 2015).

Shobert, Benjamin. 2014. Myanmar Healthcare Report 2013-2014. Edition Number 1 Rubicom Strategy Group, Asian Market Series. New York: Two Union Square.

Sippy, Sameer, and Thilaka Ravi. 2015. Health Insurance Awareness. MeDIndia. Available online: http: / / www.medindia.net/patients/insurance/awareness-healthcare-insurance-india-reference.htm (accessed on 24 August 2015).

Smith, Peter C., and Sopie N. Witter. 2004. Risk Pooling in Health Care Financing: The Implications for Health System Performance. Health, Nutrition and Population Discussion Paper. Washington: Wold Bank.

Soors, Werner, Narayanan Devadasan, Varatharajan Durairaj, and Bart Criel. 2010. Community Health Insurance and Universal Coverage: Multiple Paths, Many Rivers to Cross. World Health Report, Background Paper, 48. Geneva: World Health Organization.

Tao, Kwan-Gett. 1995. Collecting Ethnographic Data: The Ethnographic Interview. Ethnomed. Available online: http:/ / ethnomed.org/about/contribute/collecting-ethnographic-data-the-ethnographic-interview (accessed on 16 August 2018).

Tessier, Lou, and Mi Win Thidar. 2014. Evaluation of the Operations of the Social Security Board, Ministry of Labour, Employment and Social Security of Myanmar. Geneva: ILO.

Thitsar, Shwegu. 2015. Government Approves Plan for Health Insurance. Myanmar Times, June 17. Available online: http:/ / www.mmtimes.com/index.php/business/15076-government-approves-plan-for-healthinsurance.html (accessed on 5 August 2015).

UNDP. 2013. Human Development Report 2013: The Rise of the South: Human Progress in a Diverse World. New York: UNDP. Wagstaff, Adam. 2009. Social health insurance re-examined. Health Economics 19: 503-17.

WHO. 2011. Sixty-Fourth World Health Assembly Resolution. Geneva: World Health Organization.

WHO. 2015a. Questions and Answers on Universal Health Coverage. Universal Health Coverage. Available online: http:/ / www.who.int/healthsystems/topics/financing/uhc_qa/en/ (accessed on 24 August 2018).

WHO. 2015b. Global Health Observatory Data Repository. Available online: http://apps.who.int/gho/portal/ uhc-health-expenditure-v3.jsp (accessed on 24 May 2018).

WHO, SEARO. 2012. Health in Myanmar. Healthcare Systems WHO. Geneva: World Health Organization, p. 13.

Wilkinson, Sue. 2004. Focus Groups: A Feminist Method. Feminist Perspectives on Social Research. New York: Oxford University Press.

World Bank. 2015. World Bank Data on Myanmar. Available online: http://data.worldbank.org/country/ myanmar (accessed on 18 February 2015). 